\title{
New photostabilizers for polystyrene based on 2,3-dihydro-(5-mercapto-1,3,4-oxadiazol-2-yl)- phenyl-2-(substituted)-1,3,4-oxazepine- 4,7-dione compounds
}

Emad Yousif ${ }^{*}$, Ayad Hameed $^{2}$, Nadia Salih ${ }^{3}$, Jumat Salimon ${ }^{3}$ and Bashar Mudhaffar Abdullah ${ }^{3}$

\begin{abstract}
The photostabilization of polystyrene (PS) films by 2,3-dihydro-(5-mercapto-1,3,4-oxadiazol-2-yl)-phenyl-2(substituted)-1,3,4-oxazepine-4,7-dione compounds was investigated. PS films containing concentration of complexes $0.5 \%$ by weight were produced by the casting method from chloroform as a solvent. The photostabilization activities of these compounds were determined by monitoring the carbonyl and hydroxyl indices with irradiation time. The changes in viscosity average molecular weight of PS with irradiation time were also tracked (using benzene as a solvent). The quantum yield of the chain scission $\left(\Phi_{c s}\right)$ of these complexes in PS films was evaluated and found to range between $3.31 \times 10^{-6}$ and $7.89 \times 10^{-6}$. Results obtained showed that the rate of photostabilization of PS in the presence of the additive follows the trend $(I>\|>I I>I V)$. According to the experimental results obtained, several mechanisms were suggested depending on the structure of the additive like UV absorption, peroxide decomposer and radical scavenger.
\end{abstract}

Keyword: Photochemistry, PS, UV-vis Spectroscopy, Photostabilizer, UV Absorber, 1,3-Oxazepine, 1,3,4-oxadiazole

\section{Background}

Polystyrene is one of the important commercial polymers, widely used in various industrial fields. One of the important uses of PS is in the manufacture of cover signals lamp of some automobiles. PS is subjected to the irradiation of sunlight on outdoor exposure (Safy \& El-Laithy, 1994).

Many polymers undergo thermal oxidative degradation during processing. Over longer periods at ambient temperature polymers also deteriorate in the solid state through autooxidation and photooxidation. In outdoor applications where the materials are exposed to UV solar radiation, the energy of this radiation is sufficient to initiate photochemical reaction leading to degradation. Plastics are commonly protected against such deterioration by the addition of antioxidants, light and heat stabilizers (Yousif et al. 2010).

\footnotetext{
* Correspondence: emad_yousif@hotmail.com

'Department of Chemistry, College of Science, AL-Nahrain University, Baghdad, Iraq

Full list of author information is available at the end of the article
}

There is a great interest at present in the photooxidative degradation of polymeric materials because macromolecules have increasingly widespread commercial applications. Synthetic, semisynthetic and natural polymers undergo degradation when exposed to the natural (Grassie \& Scott, 1985).

All commercial organic polymers degrade in air when exposed to sunlight as the energy of sunlight is sufficient to cause the breakdown of polymeric $\mathrm{C}-\mathrm{C}$ bonds as a consequence of degradation. The resulting smaller fragments do not contribute effectively to the mechanical properties and the polymeric article becomes brittle. Thus the life of thermoplastics for outdoor applications becomes limited due to weathering (Andrady et al. 1998).

Almost all synthetic polymers require stabilization against adverse environmental effects. It is necessary to find a means to reduce or prevent damage induced by environmental components such as heat, light or oxygen. This can be achieved through addition of special chemicals, light or UV stabilizers, that are selected to be compatible with the resin and the specific application 
considered. The photostabilization of polymers may be achieved in many ways. The following stabilizing systems have been developed, which depend on the action of stabilizer. a) Light screeners. b) U.V. absorbers, c) Excited state quenchers, d) Peroxide decomposers and e) Free radical scavengers, of these it is generally believed that types c), d) and e) are the most effective.

There has been no attempt to investigate the photostabilization of PS films using 1,3-oxazepine compounds containing 1,3,4-oxadiazole units. The design of 1,3- oxazepine compounds and their use as photostabilizing agents for polystyrene are reported herein.

\section{Results and discussion}

2,3-dihydro-(5-mercapto-1,3,4-oxadiazol-2-yl)-phenyl-2(substituted)-1,3,4-oxazepine- 4,7-dione compounds have been used as additives for the photo stabilization of PS films. To assess the effectiveness of these additives for the photostabilization of PS films changes in the infrared spectra of these materialswere monitored as a function of

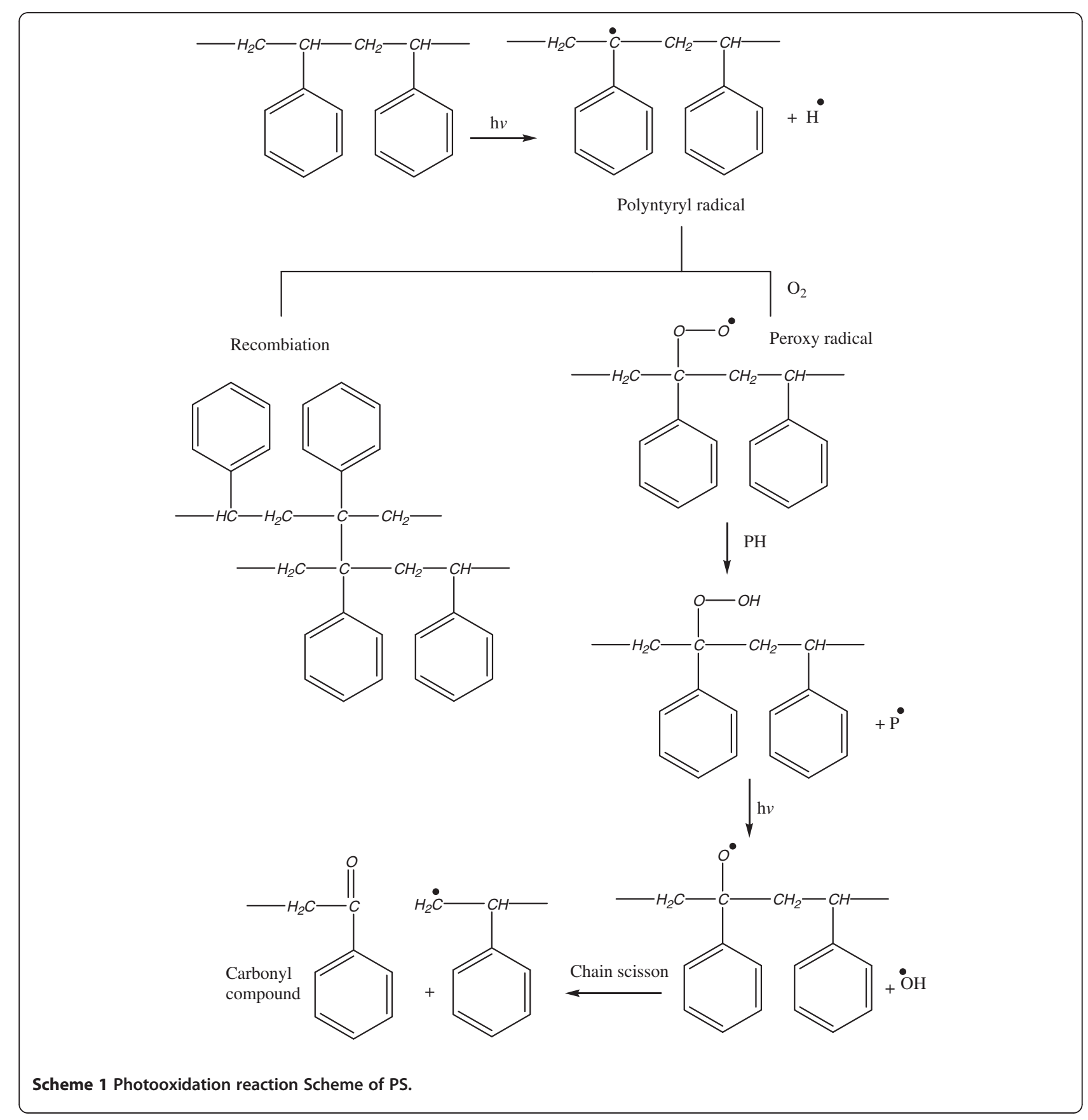




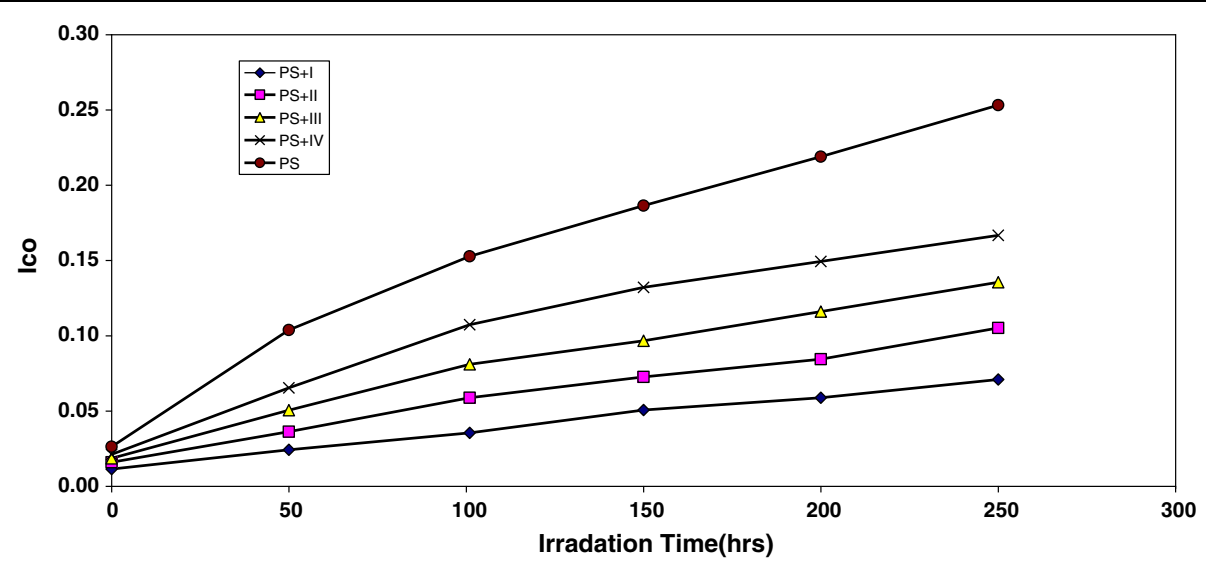

Figure 1 The relationship between the carbonyl index and irradiation time for PS films ( $40 \mu \mathrm{m}$ thickness) containing different additives. Concentration of additives is fixed at $0.5 \%$ by weight.

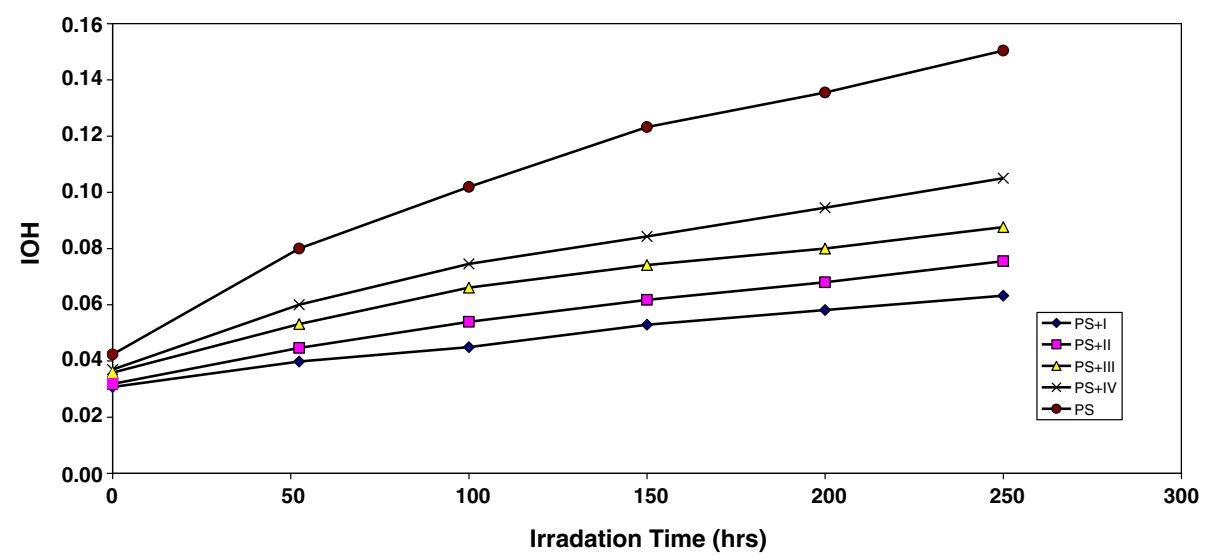

Figure $\mathbf{2}$ The relationship between the hydroxyl index and irradiation time for PS films (40 $\mu \mathrm{m}$ thickness). Containing different additives concentration of additives are fixed at $0.5 \%$ by weight.

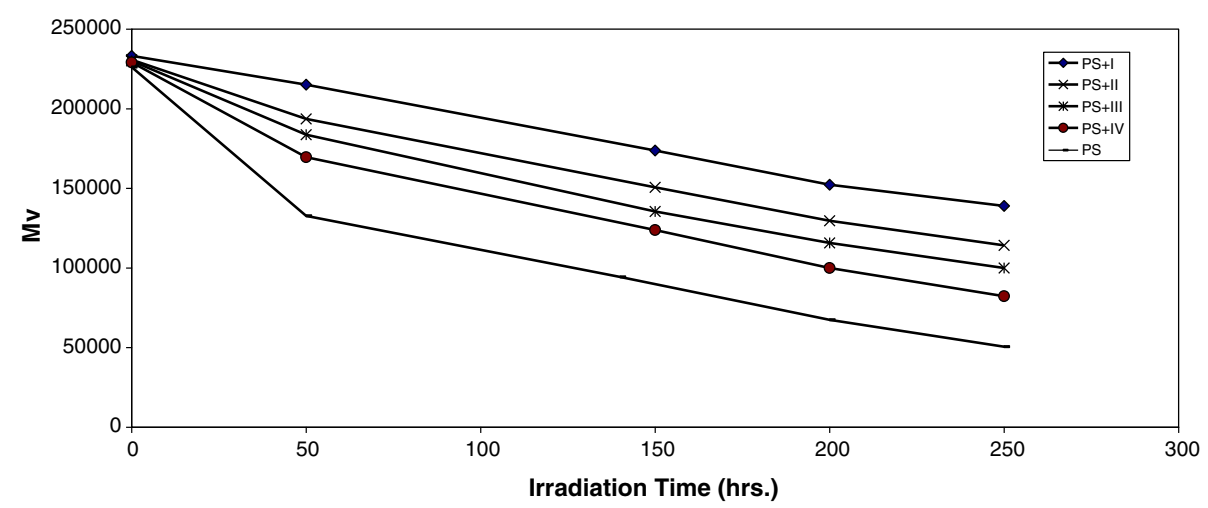

Figure 3 Changes in the viscosity-average molecular weight (Mv) during irradiation of PS films ( $40 \mu \mathrm{m})$ (blank) and with 0.5 wt $\%$ of additives. 


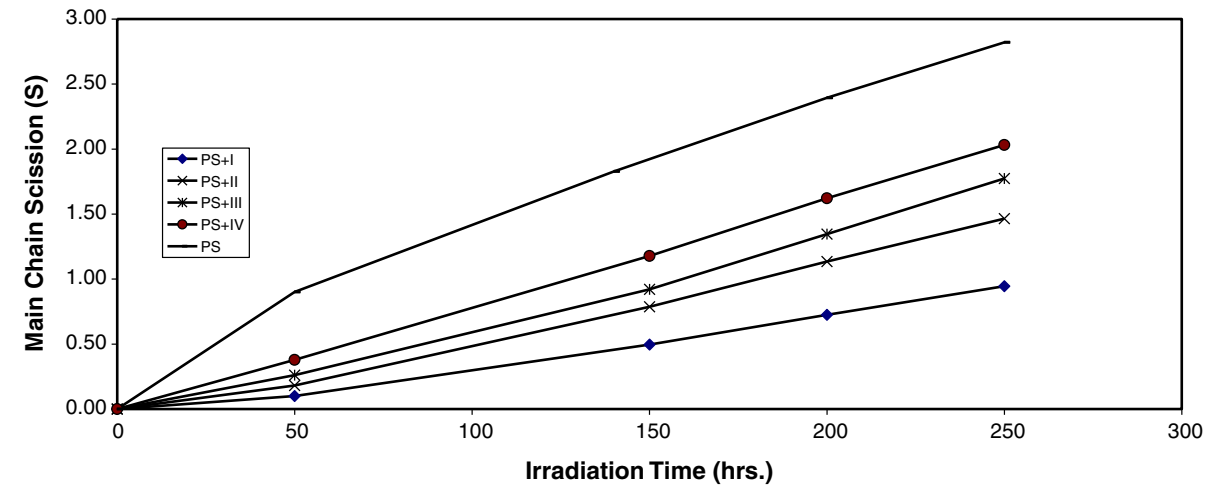

Figure 4 Changes in the main chain scission (S) during irradiation of PS films ( $40 \mu \mathrm{m})$ (blank) and with 0.5 wt $\%$ of additives.

irradiation time at $313 \mathrm{~nm}$. This irradiation altered the structure of the polymer as noted by distinct changes in the spectra. Most notable was the appearance of absorption bands characteristic of carbonyl $\left(1720 \mathrm{~cm}^{-1}\right)$ and hydroxyl groups $\left(3450 \mathrm{~cm}^{-1}\right)$. (Andrady \& Searle, 1989).

The absorption of the carbonyl and hydroxyl groups was used to follow the extent of polymer degradation during irradiation. This absorption was calculated as carbonyl index $\left(\mathrm{I}_{\mathrm{co}}\right)$ and hydroxyl index $\left(\mathrm{I}_{\mathrm{OH}}\right)$. It is reasonable to assume that the growth of carbonyl index is a measure to the extent of degradation. A probable mechanism illustrating the experimental finding can be represented as follows (Safy \& El-Laithy, 1994) (Scheme 1):

However, in Figure 1, the $\mathrm{I}_{\mathrm{co}}$ of IV, III, II, and I showed lower growth rate with irradiation time with respect to the PS control film without additives. Since the growth of carbonyl index with irradiation time is lower than PS control, as seen in Figure 1, it is suitable to conclude that these additives might be considered as photostabilizers of PS polymer. Efficient photostabilizer shows a longer induction period. Therefore, the I considered as the most active photostabilizer, followed by II, III, and VI which is the least active. Just like carbonyl, hydroxyl compounds are also produced during photodegradation of PS. Therefore, hydroxyl index could also be monitored with irradiation time in the presence and absence of these additives. Results are shown in Figure 2.

\section{I) Variation of Ps molecular weight during photolysis in the presence of by 1,3-oxazepine compounds}

Analysis of the relative changes in viscosity average molecular weight $\left(\bar{M}_{v}\right)$, has been shown to provide a versatile test for random chain scission. Figure 3 shows the plot of $\bar{M} v$ versus irradiation time for PS film with and without $0.5 \%$ (wt/wt) of the selected additives, with absorbed light intensity of $1.052 \times 10^{-8}$ ein. $\mathrm{dm}^{-3} \cdot \mathrm{s}^{-1} \cdot \bar{M} v$ is measured using equation (3) with benzene as a solvent at $25^{\circ} \mathrm{C}$.

It is worth mentioning that traces of the films with additives are not soluble in chloroform indicating that crosslinking or branching in the PS chain does occur during the course of photolysis (Mori et al. 1977). For better support of this view, the number of average chain scission (average number cut per single chain) (S) (Shyichuk \& White 2000) was calculated using the equation (8):

$$
S=\left(\bar{M}_{v, 0} / \bar{M}_{v, t}\right)-1
$$

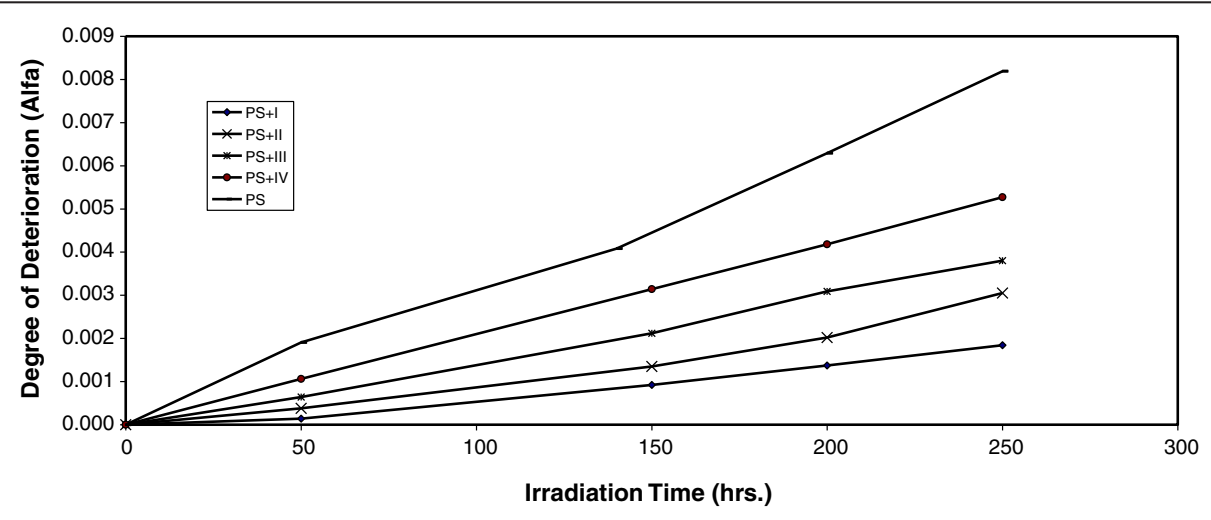

Figure 5 Changes in the degree of deterioration (a) during irradiation of PS films $(40 \mu \mathrm{m})($ blank) and with 0.5 wt $\%$ of additives. 
Table 1 Quantum yield (Фcs) for the chain scission for PS films $(40 \mu \mathrm{m})$ thickness with and without 0.5 (wt/wt) additive after $\mathbf{2 5 0} \mathrm{hrs}$ irradiaton time

\begin{tabular}{ll}
\hline Additive $\mathbf{0 . 5 \%}(\mathbf{w t} / \mathbf{w t})$ & Quantum yield of main chain scission $\left(\Phi_{\mathbf{c s}}\right)$ \\
\hline $\mathrm{PS}+$ I & $3.31 \mathrm{E}-06$ \\
$\mathrm{PS}+\mathrm{II}$ & $4.20 \mathrm{E}-06$ \\
$\mathrm{PS}+$ III & $5.78 \mathrm{E}-06$ \\
$\mathrm{PS}+$ IV & $6.25 \mathrm{E}-06$ \\
PS(blank) & $9.67 \mathrm{E}-05$ \\
\hline
\end{tabular}

Where $\bar{M}_{v, o}$ and $\bar{M}_{v, t}$ are viscosity average molecular weight at initial (0) and t irradiation time respectively. The plot of $\mathrm{S}$ versus time is shown in Figure 4. The curve indicates an increase in the degree of branching such as that might arise from cross-linking occurrence. It is observed that insoluble material was formed during irradiation which provided an additional evidences to the idea that cross-linking does occur.

For randomly distributed weak bond links, which break rapidly in the initial stages of photodegradation, the degree of deterioration $\alpha$ is given as:

$$
\alpha=\frac{m \cdot s}{\bar{M}_{v}}
$$

Where $\mathrm{m}$ is the initial molecular weight.

The plot of $\alpha$ as a function of irradiation time is shown in Figure 5.

The values of $\alpha$ of the irradiated samples are higher when additives are absent and lower in the presence of additives compared to the corresponding values of the additive free PS. In the initial stages of photodegradation of PS, the value of $\alpha$ increases with time, these indicators indicates a random breaking of bonds in the polymer chain.

Another way of degradation reaction characterization is the measurement of the quantum yield of the chain scission $\left(\Phi_{\mathrm{cs}}\right)$. The quantum yield for chain scission was calculated for PS films with and without $0.5 \%$ (wt/wt) of additive mentioned above using relation (5). The $\Phi_{\mathrm{cs}}$ values for complexes are tabulated in Table 1.

The $\Phi_{\mathrm{cs}}$ values for PS films in the presence of additive are less than that of additive free PS (blank), which increase in the order:

I, II, III, and IV

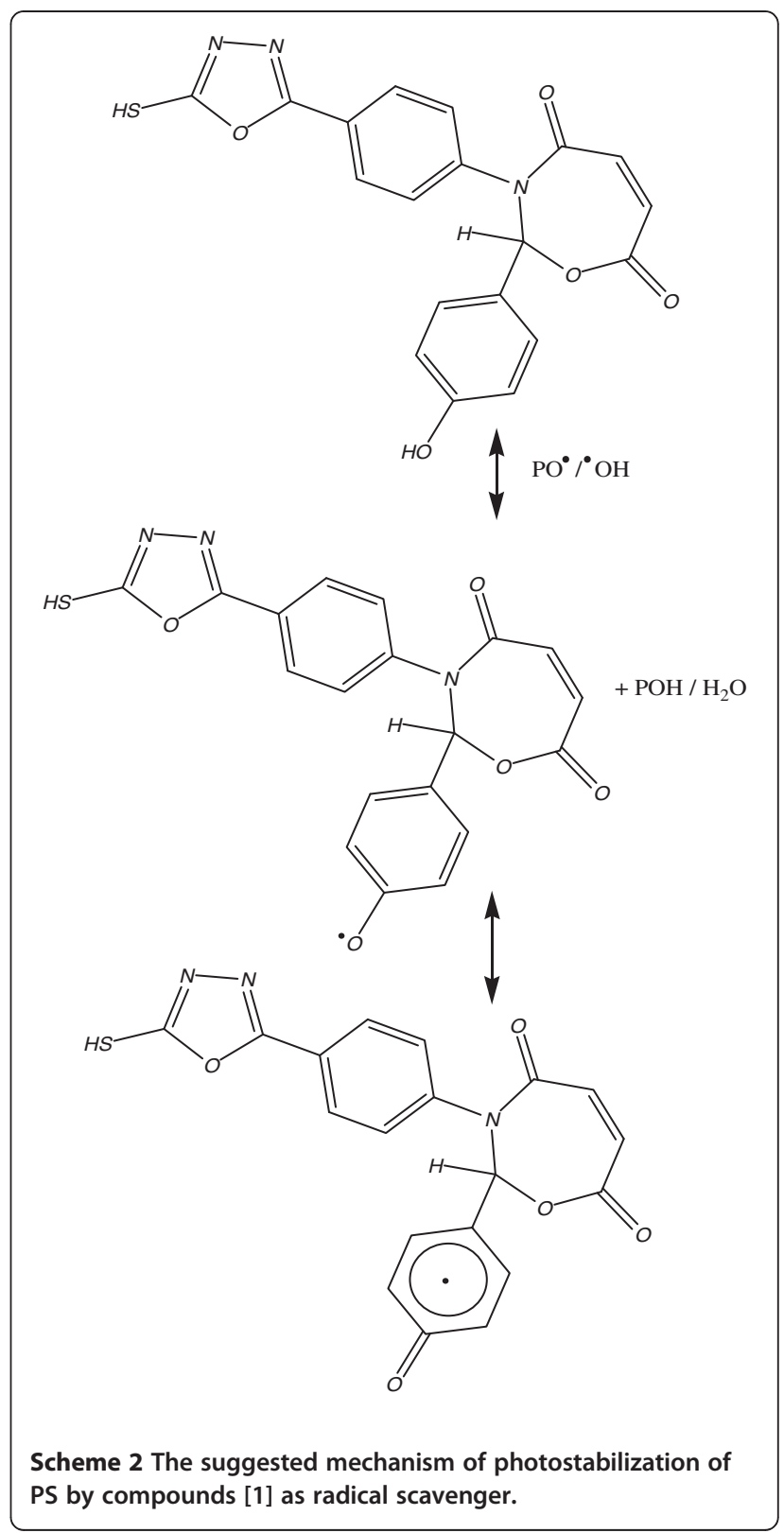

The explanation for low values of $\Phi_{\mathrm{cs}}$ is that in macromolecule of PS, the energy is absorbed at one site, and then the electronic excitation is distributed over many bonds so that the probability of a single bond breaking is small, or the absorbed energy is dissipated by non reactive processes. 


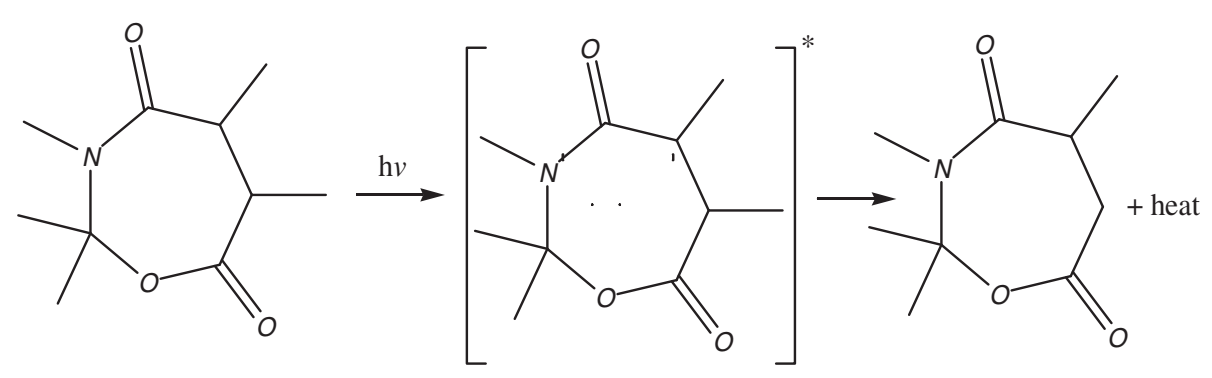

Scheme 3 Suggested mechanism of photostabilization of 1,3-Oxazepine ring as UV absorber.

II) Suggested mechanisms of photostabilization of Ps by 1,3-oxazepine compounds

1,3-Oxazepine compounds stabilize PS by different mechanisms such as UV absorber, screener or by radical scavenger. These stabilizers provide very good long-term stability and are usually referred to these mechanisms. The most probable mechanisms involved in a photostabilization is the hydroxyl group of the additive might acts as radical scavenger for photostabilization process. Therefore this Schiff bases, besides acting as UV absorber they may also act as radical scavenger additives ${ }^{19}$, Scheme 2 . The rings of oxazepine play a role in the mechanism of the stabilizer process by acting as UV absorber. The UV light absorption by these additives containing 1,3-Oxazepine dissipates the UV energy to harmless heat energy Scheme 3. The ring of 1,3,4-oxadiazole in this compound plays a role in the mechanism of the stabilizer process by acting as UV absorber. The UV light absorption by these additives containing 1,3,4- oxadiazole dissipates the UV energy to harmless heat energy Scheme 4, which support these compounds as photostabilizer.

\section{Experimental}

\section{Materials}

The following 2,3-dihydro-(5-mercapto-1,3,4-oxadiazol2-yl)-phenyl-2-(substituted)-1,3,4-oxazepine- 4,7-dione compounds were all prepared by the method previously described by (Hameed 2012) (Scheme 5).

\section{Experimental techniques}

\section{I) Films preparation}

Commercial polystyrene supplied by Petkim Company (Turkey) was re-precipitated from chloroform solution by alcohol several times and finally dried under vacuum at room temperature for 24 hours. Fixed concentrations of polystyrene solution $(5 \mathrm{~g} / 100 \mathrm{ml})$ in chloroform were used to prepare polymer films with $40 \mu \mathrm{m}$ thickness (measured by a micrometer type $2610 \mathrm{~A}$, Germany). The films were prepared by evaporation technique at room temperature for 24 hours (Sastre et al. 1990). To remove the possible residual chloroform solvent, film samples were further dried at room temperature for three hours under reduced pressure. The films were fixed on stands specially used for irradiation. The stand is provided with an aluminum plate (0.6 mm in thickness) supplied by Q-panel company.

\section{II) Irradiation experiments}

Accelerated testing technique Accelerated weatherometer Q.U.V. tester (Q. panel, company, USA), was used for irradiation of PS films. The accelerated weathering tester contains stainless steel plate, which has two holes in the front side and a third one behind. Each side contains a lamp (type Fluorescent Ultraviolet Lights) 40 Watt each. These lamps are of the type UV-B 313 giving spectrum range between 290-360 $\mathrm{nm}$ with a maximum wavelength $313 \mathrm{~nm}$. The polymer film samples were vertically fixed parallel to the lamps to make sure that the UV incident radiation is perpendicular to the samples. The irradiated samples were rotated from time to time to ensure that the intensity of light incident on all samples is the same.

\section{III) Photodegradation measuring methods}

A. Measuring the photodegradation rate of polymer films using infrared spectrophotometery The degree of photodegradation of polymer film samples was followed<smiles>CCCCC(C)(C)c1nnc(C)o1</smiles>

Scheme 4 Suggested mechanism of photostabilization of 1,3,4- oxadiazole ring as UV absorber. 

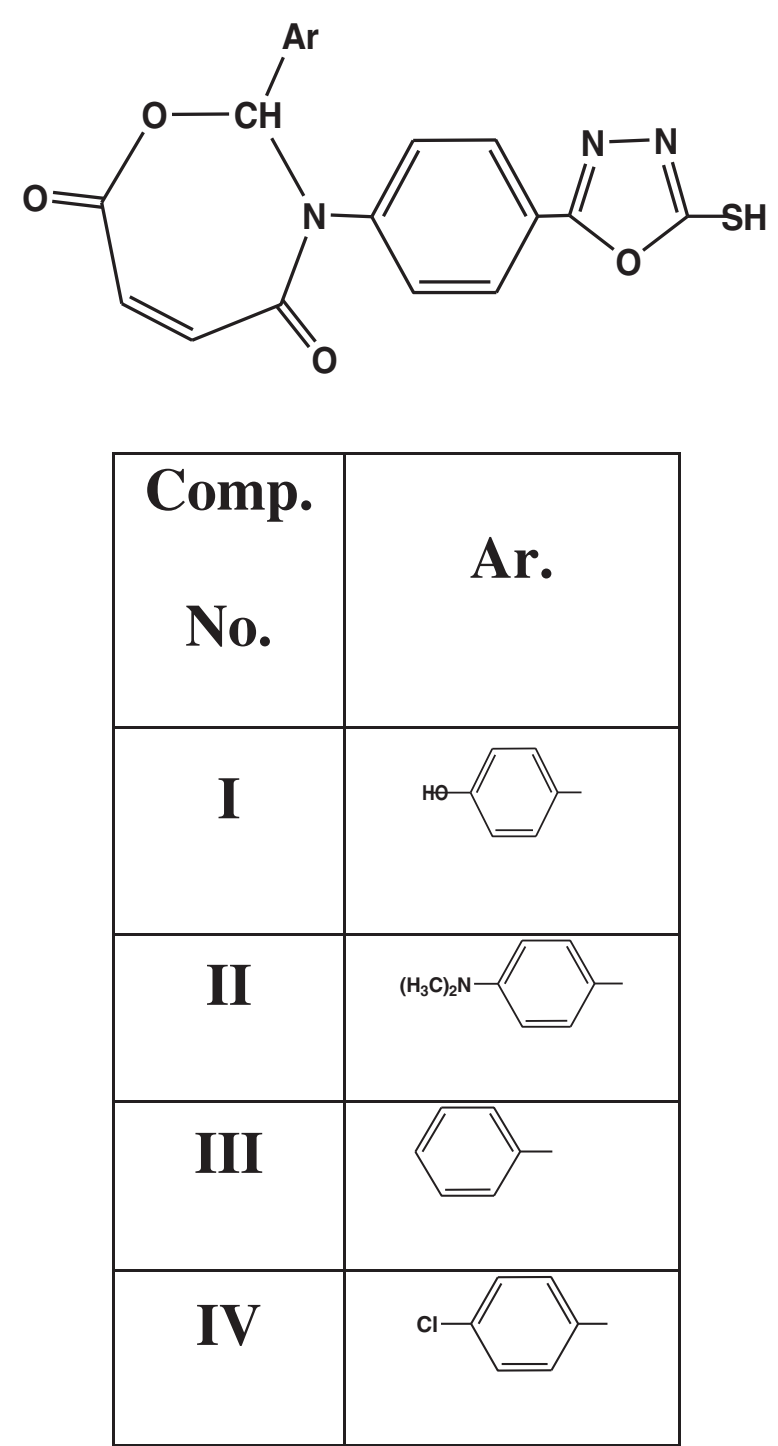

Scheme 5 (2,3-dihydro-(5-mercapto-1,3,4-oxadiazol-177 2-yl)phenyl-2-(substituted)-1,3,4-oxazepine- 4,7-dione compounds)

by monitoring FTIR spectra in the range $4000-400 \mathrm{~cm}^{-1}$ using FTIR 8300 Shimadzu Spectrophotometer. The position of carbonyl absorption is specified at $1720 \mathrm{~cm}^{-1}$ and the hydroxyl group at $3450 \mathrm{~cm}^{-1}$ (Rabek \& Ranby, 1975). The progress of photodegradation during different irradiation times was followed by observing the changes in carbonyl and hydroxyl peaks. Then carbonyl and hydroxyl indices were calculated by comparison of the FTIR absorption peak at 1720 and $3450 \mathrm{~cm}^{-1}$ with reference peak at $1450 \mathrm{~cm}^{-1}$ respectively. This method is called band index method which includes (Rabek \& Ranby, 1975):

$$
\mathrm{Is}=\frac{\mathrm{As}}{\mathrm{Ar}}
$$

As $=$ Absorbance of peak under study

$\mathrm{Ar}=$ Absorbance of reference peak

Is = Index of group under study

Actual absorbance, the difference between the absorbance of top peak and base line (A Top Peak - A Base Line) is calculated using the Base Line method (Rabek \& Ranby, 1975).

B. Determination of average molecular weight $\left(\bar{M}_{v}\right)$ using viscometry method.

The viscosity property was used to determine the average molecular weight of polymer, using the Mark- Houwink relation (Mark, 2007).

$$
[\eta]=K \bar{M}_{v}^{\alpha}
$$

$[\eta]=$ the intrinsic viscosity

$\mathrm{K}, \alpha$ are constants depending upon the polymer-solvent system at a particular temperature.

The intrinsic viscosity of a polymer solution was measured with an Ostwald U-tube viscometer. Solutions were made by dissolving the polymer in a solvent $(\mathrm{g} / 100 \mathrm{ml})$ and the flow times of polymer solution and pure solvent are $t$ and $t_{0}$ respectively. Specific viscosity $\left(\eta_{\mathrm{sp}}\right)$ was calculated as follows:

$$
\eta_{\mathrm{re}}=\frac{t}{t_{0}}
$$

$\eta_{\mathrm{re}}=$ Relative viscosity.

$$
\eta_{\mathrm{sp}}=\eta_{\mathrm{re}}-1
$$

The single - point measurements were converted to intrinsic viscosities by the relation 2 .

$$
[\eta]=(\sqrt{2} / c)\left(\eta_{\mathrm{sp}}-\ln \eta_{\mathrm{re}}\right)^{1 / 2}
$$

$\mathrm{C}=$ Concentration of polymer solution $(\mathrm{g} / 100 \mathrm{ml})$.

By applying equation 5, the molecular weight of degraded and undergirded polymer can be calculated. Molecular weights of PS with and without additives were calculated from intrinsic viscosities measured in benzene solution using the following equation;

$$
[\eta]=4.17 \times 10^{-4} \mathrm{Mv}^{0.6}
$$

The quantum yield of main chain scission $\left(\phi_{\mathrm{cs}}\right)$ (Nakajima et al. 1990) was calculated from viscosity measurement using the following relation (9).

$$
\varphi_{\mathrm{cs}}=\left(\mathrm{CA} / \bar{M}_{v, o}\right)\left[\left(\left[\eta_{o}\right] /[\eta]\right)^{1 / \alpha}-1\right] / I_{o} t
$$

Where: $\mathrm{C}=$ concentration; $\mathrm{A}=$ Avogadro's number; $\left(\bar{M}_{v, o}\right)=$ the initial viscosity-average molecular weight; 
$\left[\eta_{\mathrm{o}}\right]=$ Intrinsic viscosity of PS before irradiation; $\mathrm{I}_{\mathrm{o}}=$ Incident intensity and $\mathrm{t}=$ Irradiation time in second.

\section{Conclusions}

In the work described in this paper, the photostabilization of PS films using 2,3-dihydro-(5-mercapto1,3,4-oxadiazol-2-yl)-phenyl-2-(substituted)-1,3,4-oxazepine 4,7-dione compounds were studied. These additives behave successfully as photostabilizer for PS films. These additives stabilize the PS films through UV absorption or screening, peroxide decomposer and radical scavenger mechanisms. The compound I was found to be the most efficient in photostabilization process according to the photostability and mechanisms mentioned above. These mechanisms support the idea of using 1,3-oxazepine compounds

\section{Competing interests}

The authors declare that they have no competing interests.

\section{Authors' contributions}

EY developed the concept analyzed the data and drafted the manuscript. BMA, AH, JS and NS advised on the methods of tests. All authors read and approved the final manuscript.

\section{Acknowledgment}

The authors would like to thank University of Al-Nahrain, and Universiti Kebangsaan Malaysia for research grant UKM-GUP-NBT-08-27-113 and UKMOUP-2012-139 and for financial support and technical assistance on this work.

\section{Author details}

'Department of Chemistry, College of Science, AL-Nahrain University, Baghdad, Iraq. ${ }^{2}$ Department of Chemistry, College of Science, Tikrit University, Salah Al-deen, Iraq. ${ }^{3}$ School of Chemical Sciences and Food Technology, Faculty of Science and Technology, Universiti Kebangsaan Malaysia, Bangi, Selangor 43600, Malaysia.

Received: 15 December 2012 Accepted: 27 February 2013

Published: 12 March 2013

\section{References}

Andrady A, Hamid S, Hu X, Torikai A (1998) Effects of increased solar ultraviolet radiation on materials. Journal of Photochemistry and Photobiology B-Biology 46:96-103

Andrady A, Searle N (1989) Photodegradation of rigid PVC formulations II. Spectral sensitivity to light-induced yellowing by polychromatic light. J Appl Poly Sci 37:2789-2802

Grassie N, Scott G (1985) Polymer Degradation and Stabilization. Cambridge University Press, London

Hameed A (2012) Microwave synthesis of some New 1,3-oxazepine compounds as photostabilizing additives for PMMA films. JAUS 15(4):47-59

Mark J (2007) Physical Properties of Polymers Handbook. Springer, New York

Mori F, Koyama M, Oki Y (1977) Studies on photodegradation of poly(vinyl chloride) (part 1)Die. Angewandte Makromolekulare Chemie 64(1):89

Nakajima N, Sadeghi M, Kyu T (1990) Swelling of PVC particles during gelation and fusion of plastisols as observed with small-angle light scattering (pages 889-899). J Appl Polymer Sci 41:889

Rabek J, Ranby B (1975) Photodegradation, photo-oxidation and Photostabilization of Polymers. John Wiley, New York

Safy N, El-Laithy S (1994) Photooxidative degradation of polystyrene of cover signals lamp of some automobiles. J Appl Polymer Sci 55:47-55
Sastre R, Catalina F, Mateo J (1990) Mechanism of photostabilization of polystyrene film by dihydroxyphenyl-pirazoles. J Appl Polymer Sci 28:3661-3668

Shyichuk A, White J (2000) Analysis of chain scission and crosslinking rates in the photooxidation of polystyrene. J Appl Polymer Sci 77(13):3015-3023

Yousif E, Hameed A, Rasheed R, Mansoor H, Farina Y, Graisa A, Salih N, Salimon J (2010) Synthesis and photostability study of some modified poly(vinyl chloride) containing pendant benzothiazole and benzimidozole ring. Inter J Chem 2(1):65-80

doi:10.1186/2193-1801-2-104

Cite this article as: Yousif et al: New photostabilizers for polystyrene based on 2,3-dihydro-(5-mercapto-1,3,4-oxadiazol-2-yl)-phenyl-2(substituted)-1,3,4-oxazepine- 4,7-dione compounds. SpringerPlus 2013 2:104.

\section{Submit your manuscript to a SpringerOpen ${ }^{\circ}$ journal and benefit from:}

- Convenient online submission

- Rigorous peer review

- Immediate publication on acceptance

- Open access: articles freely available online

- High visibility within the field

- Retaining the copyright to your article

Submit your next manuscript at $>$ springeropen.com 